\title{
ОМЕНТИН, КАК ОБЪЕКТИВНЫЙ ПОКАЗАТЕЛЬ ВЕРОЯТНОСТИ НАРУШЕНИЯ УГЛЕВОДНОГО И ЛИПИДНОГО ОБМЕНА ПРИ ОЖИРЕНИИ БЕРЕМЕННЫХ ЖЕНЩИН В ПЕРВОМ ТРИМЕСТРЕ ГЕСТАЦИИ
}

\section{OMENTIN AS AN OBJECTIVE INDICATOR OF THE PROBABILITY OF IMPAIRED CARBOHYDRATE AND LIPID METABOLISM IN OBESE PREGNANT WOMEN IN THE FIRST TRIMESTER OF GESTATION}

N. Datsenko

A. Yakimova

Summary. Many researchers around the world report an alarming increase in the prevalence of obesity among all age groups, including women of reproductive age. The idea of the function of adipose tissue as just a fat depot has changed in recent years. Currently, the main focus is on the metabolic functions of adipose tissue, which are modulated by adipocytokines. Adipocytokines have been found to control insulin sensitivity, inflammatory activity, neuroendocrine activity, food and water consumption, reproduction, and bone metabolism. Omentin-1 is an adipocytokine with anti-inflammatory activity that is associated with various metabolic disorders. The aim of our study is to study the serum profiles of omentin-1, the relationship between levels of omentin- 1 and insulin resistance during pregnancy in women with varying degrees of obesity in comparison with pregnant women with normal BMI. Our study showed that obese pregnant women had significantly lower serum concentrations of omentin-1 compared to the control group. Serum concentrations of omentin-1 are significantly lower in patients with grade III obesity compared to patients suffering from the first and second degrees of obesity. Accordingly, we can conclude that the concentration of serum omentin- 1 is associated with the presence and severity of obesity in pregnant women. In addition, the article shows the relationship of serum omentin-1 with the concentration of TG, cholesterol, immunoreactive insulin and glycosylated hemoglobin in the blood of patients.

Keywords: pregnancy, omentin-1, obesity, insulin resistance, glycated hemoglobin.

\author{
Даценко Наталья Сергеевна \\ Ассистент, Новосибирский государственный \\ медицинский университет \\ Datsenko.natasha@yandex.ru \\ якимова Анна Валентиновна \\ Д.м.н., профессор, Новосибирский государственный \\ медицинский университет \\ a.yakimova2@yandex.ru
}

Аннотация. Множество исследователей в мире говорят о катастрофическом росте распространения ожирения среди всех возрастных групп, в том числе, - среди женщин репродуктивного возраста. Представление о функции жировой ткани, как просто о жировом депо изменилось в последние годы. В настоящее время основное внимание уделяется метаболическим функциям жировой ткани, которые модулируются с помощью адипоцитокинов. Было обнаружено, что адипоцитокины контролируют чувствительность к инсулину, воспалительную активность, нейроэндокринную активность, потребление пищи и воды, размножение и метаболические процессы в костной ткани. Оментин-1 является адипоцитокином с противовоспалительной активностью, который связан с различными нарушениями обмена веществ. Целью нашего исследования является оценить связь уровня оментина-1 в сыворотке крови беременных женщин со степенью ожирения и наличием у них инсулинорезистентности. Наше исследование показало, что беременные с ожирением имели значительно более низкие сывороточные концентрации оментина-1 по сравнению с группой контроля. Сывороточные концентрации оментина-1 значительно ниже у пациенток c III степенью ожирения по сравнению с пациентками, страдающими первой, второй степенями ожирения. Соответственно можно сделать вывод о существовании связи концентрации сывороточного оментина-1 с наличием и степенью выраженности ожирения у беременных женщин. Кроме того, в статье показана связь сывороточного оментина-1 с концентрацией в крови пациенток ТГ, холестерина, иммунореактивного инсулина и гликозилированного гемоглобина.

Ключевые слова: беременность, оментин-1, ожирение, инсулинорезистентность, гликозилированный гемоглобин. 


\section{Ввемение}

$\mathbf{0}$ жирение - это серьезная клинико-социальная проблема, затрагивающая большое количество людей на земном шаре. Избыточный вес рассматривается Всемирной Организацией Здравоохранения, как одна из самых больших глобальных угроз, затрагивающих более 39\% мирового населения [1]. Неблагоприятным фоном для развития беременности является так же ожирение матери, вне зависимости от выраженности и степени. У каждой второй беременной, страдающей ожирением, развивается преэклампсия, у каждой третьей - угроза невынашивания беременности, гестационный сахарный диабет, задержка роста плода, формирование чрезмерно крупного плода. Так же в три раза увеличивается вероятность развития инфекции мочевыводящих путей. Возрастает риск осложнений в родах: преждевременного излития околоплодных вод, дистоция плечиков плода, слабости родовой деятельности, что приводит к увеличению неблагоприятных перинатальных исходов [2]. Жировая ткань - это самая крупная метаболически активная эндокринная структура в организме человека. Адипоциты вырабатывают и секретируют целый ряд биологически активных веществ, в том числе адипоцитокины, ферменты, факторы роста и гормоны. Эти соединения регулируют множество процессов в организме: воспаление, иммунитет, питание и поддержании энергетического баланса, чувствительность к инсулину, метаболизм углеводов и липидов, гемостаз, ангиогенез, артериальное давление. Результаты клинических исследований последних лет показывают, что адипоцитокины могут быть ответственны за хроническое субклиническое воспаление при ожирении. Жировая ткань может быть источником провоспалительных медиаторов, которые могут непосредственно вызывать поражение эндотелия сосудов, инсулинорезистентность и, как следствие, развитие атеросклероза. Такие эффекты могут быть вызваны ФНО-а, ИЛ-1, ИЛ-6, СРБ, лептином, резистином, пай-1 и ангиотензиногеном. Другие вещества, продуцируемые адипоцитами, такие как оксид азота и адипонектин, оказывают противовоспалительное действие и снижают инсулинорезистентность [3]. Нормальная беременность связана с высокорегулируемой воспалительной реакцией и существует баланс между противовоспалительными и воспалительными факторами. Воспалительная реакция необходима для правильной имплантации трофобласта. В отличие от этого, постимплантационный период связан с иммуносупрессией для предотвращения иммунного отторжения плода. Материнское ожирение связано с диспропорцией медиаторов воспаления, что в конечном итоге может привести к нарушениям, характерным для беременности, осложненных ожирением матери [4]. На сегодняшний день в литературе представлено недостаточно данных о роли провоспалительного адипоци- токина- оментина-1 во время беременности. Оментин-1 впервые был идентифицирован из висцеральной жировой ткани в 2003 году [5]. Существует две высокогомологичные изоформы оментина: оментин-1 и оментин-2, однако оментин-1 является основной циркулирующей формой в плазме крови человека [6]. Выявлена его обратная связь с ожирением, сахарным диабетом 2 типа, метаболическим синдромом и синдромом поликистозных яичников (СПКЯ) [7]. Оментин-1 усиливает действие инсулина. Уровень оментина повышается после потери веса и понижается под влиянием инсулина и глюкозы $[8,9]$.

\section{Цель исслеАования}

Оценить связь уровня оментина-1 в сыворотке крови беременных женщин со степенью ожирения и наличием у них инсулинорезистентности.

\section{Материалы и метомы}

В исследование были включены 200 беременных женщин с ожирением, родившие живых детей в доношенном сроке. Диагноз ожирения выставляли на основании определения индекса массы тела (ИМТ) в сроке беременности до 9 недель. Были сформированы 4 группы женщин. Три опытные группы: I группа - беремен-

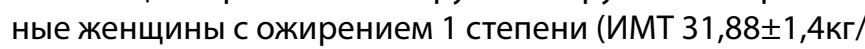
$\left.\mathrm{M}^{2}\right)$, II - беременные женщины с ожирением 2 степе-

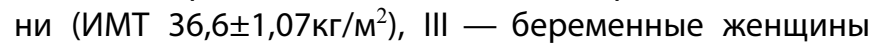
с ожирением 3 степени (ИМТ42,2 $\left.2 \pm 1,9 \mathrm{kг} / \mathrm{M}^{2}\right) \quad(\mathrm{p} \leq 0,05)$. В контрольную группу вошли беременные женщины с нормальным ИМТ $\left(21 \pm 1,88 \mathrm{kr} / \mathrm{M}^{2}\right)$. Средний возраст

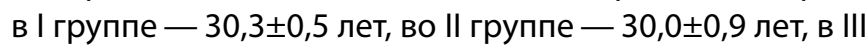
группе - 33,5 $\pm 0,8$ лет. В контрольной группе средний возраст 28,5 $\pm 0,7$ лет. Во всех четырех группах преобладали повторнородящие женщины. Уровень гликемии в плазме венозной крови определялся натощак (глюкозооксидазным методом на биохимическом анализаторе «Screen Master Plus», Hospitex diagnostic, Швейцария). Иммунореактивный инсулин исследовали методом иммуноферментного анализа на аппарате «Ахsym» фирмы Abbot, США). Инсулинорезистентность оценивали по индексу HOMA-IR (ИРИ × гликемия натощак / 22,5). Уровень оментина-1 в сыворотке крови определяли методом иммуноферментного анализа с помощью набора «ELISA» до 8 недель гестации. Статистическая обработка данных проводилась с помощью пакета Statistica7.0 для Windows. Критерий Манна-Уитни применялся для определения статистической обоснованности различия исследуемых групп.

Критерии исключения: женщины с преэклампсией, с хронической артериальной гипертензией, подтвержденным гестационным сахарным диабетом. 


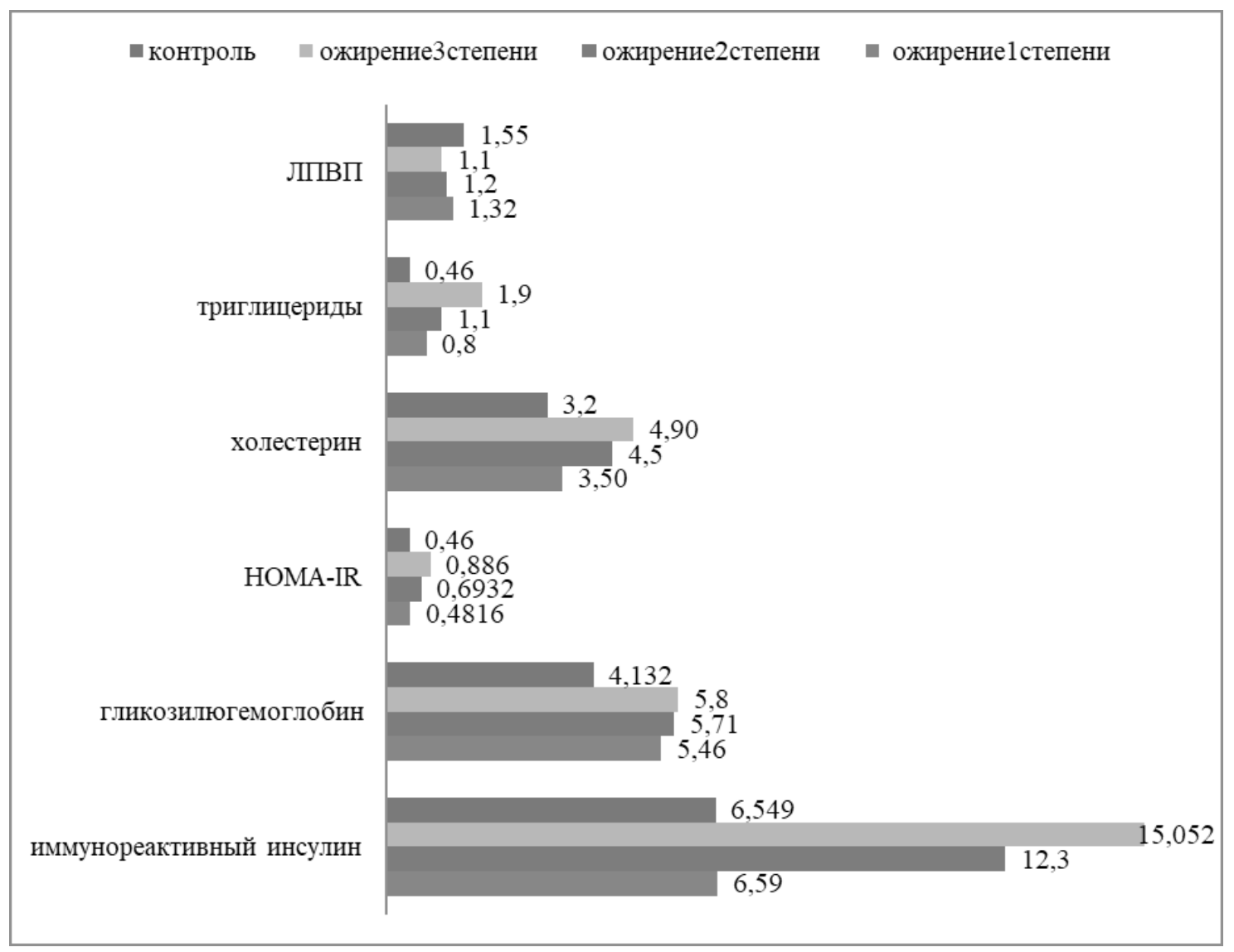

Рис. 1. Лабораторные показатели по группам в сравнении с контролем. *P<0,05.

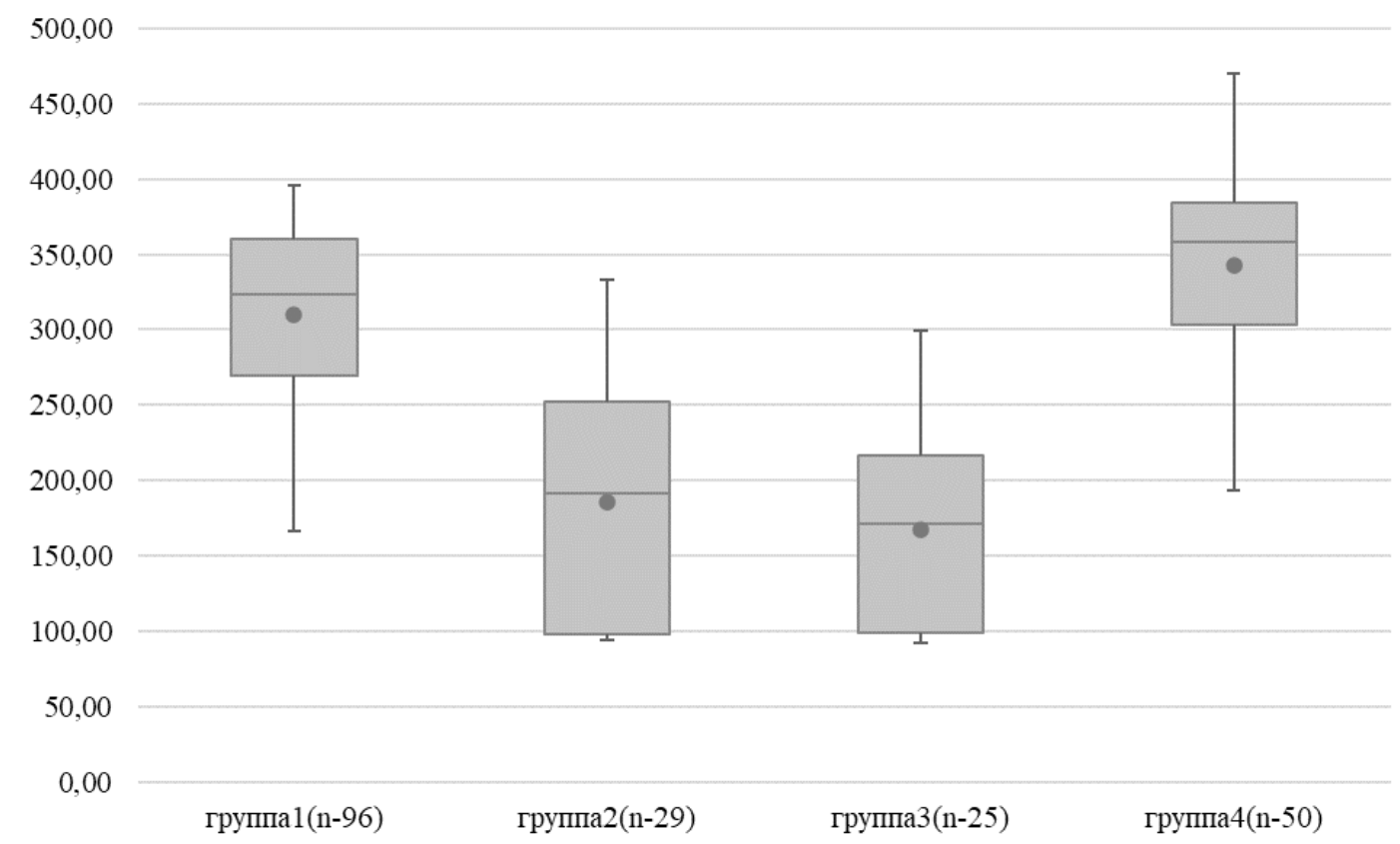

Рис. 2. Концентрации в сыворотке крови omentin-1 у беременных с разной степенью ожирения и у беременных контрольной группы. ${ }^{*} \mathrm{P}<0,05$. 


\section{Результаты исслеАования} и их обсужление

Результаты определения исследуемых показателей пациенток с ожирением и контрольной группы представлены на рисунке 1. Пациентки с ожирением имели более высокие концентрации холестерина, иммунореактивного инсулина, гликозилированного гемоглобина, HOMA-IR и TГ, а также более низкие концентрации ЛПВП по сравнению с контрольной группой. Достоверных различий по другим характеристикам между этими группами выявлено не было.

Сывороточные концентрации оментина-1 у пациенток с ожирением и здоровых беременных контрольной группы показаны на рисунке 2.

Пациенты с ожирением имели достоверно более низкие концентрации оментина-1 в сыворотке крови, чем в контроле $(\mathrm{P}<0,05)$. Согласно вычисленному коэффициенту корреляции, имела место обратная зависимость между степенью ожирения и уровнем оментина-1 (r=).

Концентрация оментина-1 в сыворотке крови также показала отрицательную корреляцию с ИМТ и НОМАIR. Насколько нам известно, это первое исследование, демонстрирующее связь концентрации сывороточного оментина-1 с наличием и тяжестью ожирения беременных женщин. По данным Haiping Liu et al., ожирение является предрасполагающим фактором в развитии преэклампсии и уровень сывороточного оментина-1 достоверно снижается при нарастании степени тяжести преэклампсии [10]. Однако, нами было впервые показано, что даже в ранних сроках беременности уровень оментина при различных степенях ожирения различается и взаимосвязан с инсулинрезистентностью и нарушением липидного обмена. Вероятно, эти сведения можно будет использовать при многофакторном анализе риска развития осложнений беременности при ожирении.

\section{Эак^ючение}

Результаты настоящего исследования показали, что пациенты с ожирением имели значительно более низкие сывороточные концентрации оментина-1 по сравнению со здоровыми беременными, что указывает на потенциальную роль отметина -1 в патофизиологии ожирения. Кроме того, сывороточные концентрации оментина-1 были значительно ниже у пациенток с III степенью ожирения по сравнению с пациентками, страдающими первой степенью ожирения. Можно сделать вывод о существовании связи концентрации сывороточного оментина-1 с наличием и степенью выраженности ожирения у беременных женщин. Кроме того, концентрация сывороточного оментина-1 показала отрицательную корреляцию не только с ИМТ, а также с концентрацией в крови беременных ТГ, холестерина, иммунореактивного инсулина и гликозилированного гемоглобина. Поскольку материнское ожирение связано с высокой вероятностью возникновения перинатальной патологии, профилактическое лечение может быть начато на ранней стадии.

\section{ЛИТЕРАТУРА}

1. Lim CC, Mahmood T: Obesity in pregnancy. Best Pract Res Clin Obstet Gynaecol, 2015; 29(3): 309-19.

2. Yang RZ, Xu AH, Pray J, Hong H, Jadhao S, et al. (2003) Cloning of omentin, a new adipocytokine from omental fat tissue in humans. Diabetes 52: A1-A1.

3. Gregor MF, Hotamisligil GS: Inflammatory mechanisms in obesity. Annu Rev Immunol, 2011; 29: 415-45

4. Pantham P, Aye IL, Powell TL: Inflammation in maternal obesity and gestational diabetes mellitus. Placenta, 2015; 36(7): 709-15

5. Makarov I.0., Borovkov E. I., Abramov M. Yu. The course of pregnancy and childbirth in women with obesity. Journal of Obstetrics, Gynecology and reproduction. 2011. Vol. 5. P. 27.

6. Batista C, Yang RZ, Lee MJ, Glynn NM, Yu DZ, et al. (2007) Omentin plasma levels and gene expression are decreased in obesity. Diabetes 56: $1655-1661$.

7. Pan HY, Guo L, Li Q (2010) Changes of serum omentin-1 levels in normal subjects and in patients with impaired glucose regulation and with newly diagnosed and untreated type 2 diabetes. Diabetes Research and Clinical Practice 88: 29-33.

8. Chu SY, Bachman DJ, Callaghan WM, Whitlock EP, Dietz PM, et al. (2008) Association between obesity during pregnancy and increased use of health care. New England Journal of Medicine 358: 1444-1453.

9. Watanabe T., Watanabe-Kominato K., Takahashi Y. et al. Adipose Tissue-Derived Omentin-1 Function and Regulation // Compr. Physiol. \ 2017. \ Vol. 7, № 3. \ P. 765-781.

10. Haiping Liu, Jianfeng Wu, Haiyu Wang, Lianbing Sheng, Ning Tang, Yunfei Li and Tianyu Hao. Association of serum omentin-1 concentrations with the presence and severity of preeclampsia// Annals of Clinical Biochemistr-2015, Vol. 52(2) 245-250 